PERSPECTIVA TEOLÓGICA ADERE A UMA LICENÇA CREATIVE COMMONS ATRIBUIÇÃO 4.0 INTERNACIONAL - (CC BY 4.0)

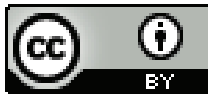

DOI: $10.20911 / 21768757 v 53 n 3 p 787 / 2021$

\title{
ENCONTRANDO A DIOS EN LO COTIDIANO COMO CAMINO DE LA PASTORAL URBANA EN EL BARRIO LA MATRIZ DE VALPARAÍso *
}

Finding God in the Mundane as an Urban Pastoral Path in Bairro Matriz, of Valparaíso

Gonzalo Arturo Bravo Álvarez **

Maite Inés Jiménez Peralta ***

RESUMEN: La ciudad latinoamericana se presenta fragmentada, requiriendo una conexión más dialéctica en la acción pastoral de la Iglesia. El in-trascendente de la revelación de Dios en el barrio permite una reflexión teológica acerca del sentido de su presencia desde lo cotidiano; lo urbano es una realidad sensible que confronta al hombre. Se presentará el "barrio puerto" en Valparaíso (Chile), que animado por la acción eclesial, permite ser repensado como un espacio de revelación. Ello propicia una pastoral urbana donde la misión evangelizadora conlleva una transformación social que potencia la dignidad humana de quienes comparten en el sector su vida cotidiana, dado que "el reino contempla una trasformación positiva de toda realidad humana".

PALABRAS-CLAVES: Pastoral urbana. Iglesia latinoamericana. Teología de lo urbano. Iglesia local. Misión evangelizadora.

\footnotetext{
* Estudio de caso realizado por los autores en barrio puerto de Valparaíso, bajo financiamiento interno de la Pontificia Universidad Católica de Valparaíso, entre los meses de abril a noviembre de 2019. Los nombres de los participantes han sido cambiados para resguardar su identidad. Los participantes, doce en total, fueron seleccionados por el método de representación por caso típico. Se les realizaron entrevistas grupales desde un enfoque biográfico, las que luego se analizaron desde la representación que estos relatos hacen de las proyecciones que el sujeto tiene de sí sobre su entorno.

** Pontificia Universidad Católica de Valparaíso, Valparaíso, Chile.

*** Pontificia Universidad Católica de Valparaíso, Valparaíso, Chile.
} 
ABSTRACT: The Latin American city appears fragmented, requiring a more dialectical connection in the pastoral action of the Church. In the neighborhood, the in-transcendence of the revelation of God allows a theological reflection on the meaning of His presence from the everyday. "The urban" is a sensitive reality that confronts the man. The "harbor district" in Valparaiso (Chile), which will be presented as animated by ecclesial action, allows it to be reconsidered as a space of revelation. This provides an urban pastoral where the evangelizing mission entails a social transformation that enhances the human dignity of those who share their daily life in the sector, given that "the kingdom contemplates a positive transformation of all human reality".

KEYWORDS: Urban pastoral. Latin American Church. Theology of the Urban. Local Church. Evangelizing mission.

\section{Introducción}

L

a historia de la evangelización es el relato de un encuentro entre la fe de la Iglesia con los pueblos, sus culturas y ciudades. Permite también comprender, cómo la vida parroquial ha necesitado replantearse, en el contexto de una nueva urbanización latinoamericana y de la reflexión sobre una iglesia diocesana, guiada hacia una pastoral comunitaria urbana, que fomente el desarrollo de comunidades cristianas, pensadas y articuladas con base en las familias. De esta manera, el barrio como espacio de encuentro en lo cotidiano, pero también de disputa y tensión ante la complejidad de la cultura urbana actual, puede pensarse como lugar de evangelización. La microesfera del barrio como lugar hermenéutico posibilita la reflexión teológica, dado que la creación y la historia constituyen el espacio y el tiempo en que Dios se revela.

Este texto propone una nueva manera de entender cómo la cotidianeidad de un barrio puede entretejerse con la acción pastoral de una parroquia y por tanto se pregunta ¿Cómo lo cotidiano es expresado en los encuentros y relatos de sus habitantes? ¿Qué impronta tiene la acción pastoral en estos relatos? Así el objetivo es explorar cómo en lo cotidiano del barrio La Matriz de Valparaíso se hace presente Dios, develando una forma de pensar el camino de la Pastoral Urbana.

Para ello, en una primera parte, se reflexiona en torno al sentido de repensar la pastoral urbana ante la complejidad de la ciudad latinoamericana y las formas de manifestación de Dios en lo cotidiano del barrio. Luego se exploran las memorias de los habitantes, en cuyos relatos se reconstruye y organiza lo cotidiano del barrio en su relación con Parroquia La Matriz. Se muestra un espacio que animado por la acción eclesial es repensado como un espacio de revelación que propicia una pastoral urbana donde 
la misión evangelizadora conlleva una transformación social que potencia la dignidad humana de quienes comparten en el sector su vida cotidiana. Finalmente se discute el rol transformador de la evangelización en la relación didáctica entre lo cotidiano y lo trascendente.

Con un propósito metodológico, el barrio es comprendido desde la perspectiva del sujeto, y se caracteriza por ser un rasgo de la personalidad de cada individuo, que le lleva a entender y comprender la realidad en el mundo y los procesos que en ella se enmarcan en variables tan importantes como la cultura, la ideología, los valores, las experiencias vividas, etc. Así tres claves lo irán definiendo como lugar hermenéutico: una temporal (historia), una espacial (paisaje urbano) y una social (el otro).

\section{Hacia una pastoral urbana. Repensando una teología de lo urbano}

Aunque la iglesia en América Latina tuvo casi un monopolio sobre las creencias y prácticas religiosas, el secularismo (HOLYOAKE, 1870, p. 5) actual provoca una hegemonía de la vivencia, o experiencia cotidiana, como fuente de la verdad, limitando la influencia de la religión en la toma de decisiones a la esfera de lo privado (KOSMIN, 2006, p. 6). Se suma la llamada "crisis urbana" ante la creciente urbanización en América Latina (GATICA, 1975, p. 10; QUIJANO, 2019, p. 669) donde más del 80\% de la población vive en zonas urbanas (CEPAL, 2012) ${ }^{1}$, con efectos como déficit de vivienda, falta de estructuración urbana, situación del empleo, entre varias más. Así, ante la reducción de la influencia política, la hegemonía religiosa y cultural de la iglesia, en democracias cada vez más pluralistas (HAGOPIAN, 2008, p. 149), es necesario plantearse el desafío de la evangelización de la ciudad moderna (BRIGHENTI, 2013, p. 357).

Se necesita proponer una inculturación del Evangelio en la cultura de la ciudad, especialmente de las megalópolis (CHEUICHE, 1988, p. 241), y proyectar una nueva pastoral urbana en la que "las dinámicas de la fe implican comienzos siempre nuevos, que no encierran la fe en lo particular, sino que la abren continuamente a la novedad" (ECKHOLT, 2018, p. 619).

Se necesita además comprender, que el modelo de ciudad latinoamericana es de una urbe privatizada y fragmentada, donde la expansión urbana puede reconocerse como un entramado de procesos de extensión de servicios y funciones urbanas sobre territorios vacantes, convergiendo

\footnotetext{
${ }^{1}$ Dos tercios de la población latinoamericana vive en ciudades de 20.000 habitantes o más y casi un $80 \%$ en zonas urbanas.
} 
hacia la construcción de fragmentos urbanos (SZUPIANI, 2018, p. 110). El resultado es una transformación de los hábitos de sus ciudadanos con tendencia hacia una ciudad extremadamente segregada y dividida (JANOSHCKA, 2002, p. 11).

Estas nuevas "ciudades islas" evidencian una desorientación pastoral en las Iglesias locales, con una inadecuada articulación del contexto urbano como su ámbito propio y directo (COMBLIN, 1972, p. 375), porque en las ciudades se produce una relación dialéctica entre el pecado y la revelación de Dios (COMBLIN, 1972, p. 32);

Es en lo urbano donde la iglesia se va asentando (FITZGERALD, 2001, p. 90), porque aunque la ciudad posee una dimensión material y permanente en sus edificios y calles, también se construye desde una dimensión inmaterial donde lo cotidiano va cargando las diversas capas de significado que articulan la identidad local de sus habitantes. Ya hace referencia a esto el Papa Francisco en Laudato si cuando señala

Hace falta cuidar los lugares comunes, los marcos visuales y los hitos urbanos que acrecientan nuestro sentido de pertenencia, nuestra sensación de arraigo, nuestro sentimiento de "estar en casa" dentro de la ciudad que nos contiene y nos une. (LS, n. 151)

Lo urbano como constructo, trata de la existencia de una comunidad que se va estructurando en conductas, mediante la apropiación de conocimientos, valores, emociones e ilusiones (y utopías). Esta cultura, particularmente en Latinoamérica, ha tenido una influencia religiosa determinante (LARRAÍN, 1984, p. 237), siendo parte constitutiva y constituyente de ella, aportándole símbolos y significados (SOLÍS BELLO, 2010, p. 262).

Porque, cuando un sujeto inmerso en la vida citadina comienza a comprender cómo la vida de Jesús incide en la situación urbana, hay un proceso necesario de autoevaluación, de concientización, de ser consciente y sensible a los factores reales que, de manera visible e invisible, determinan la situación (VINCENT, 1983, p. 8). Una teología de lo urbano es la reflexión teológica de los cristianos urbanos sobre la situación en la que viven y sobre su lucha por la liberación (NEWMANN, 2018, p. 297; VINCENT, 1983, p. 4).

La teología en el contexto de los pobres urbanos requiere una consideración cuidadosa porque involucra a las comunidades humanas. Necesita re-aprender a asumir esta complejidad para estar con ella humildemente y con espíritu de compartir en la perseverancia de la caridad (FORTE, 1990, p. 39).

En la ciudad, la religiosidad se transforma en una peculiar profanación de lo sagrado y una curiosa sacralización de lo profano. Aparece cargada con una profunda ambigüedad y ambivalencia, entre la libertad, la creativi- 
dad, el desarrollo, junto con el anonimato, el crecimiento de la violencia, la explotación o la exclusión, relevantes en el momento de pensar en una actitud evangelizadora (BUENO, 2016, p. 2).

También es escenario de una mentalidad urbana donde confluyen distintos modos de pensar y estilos de vida, caracterizado, cada vez más, por la heterogeneidad de grupos diversos y a veces enfrentados en una multiculturalidad vivida como experiencia nueva de libertad y de fragmentación, como "aliento de emancipación" (BUENO, 2016, p. 1).

Se da, así, una llamada a contextualizar el quehacer teológico urbano, comprometiéndose con la visibilidad de las personas en situación de desplazamiento, en la búsqueda de su espacio con sentido y significado (VÉLEZ et al., 2014, p. 396). Esto es lo que está en la base de una constatación: la Iglesia nació urbana. Es por ello por lo que una ciudad fragmentada es una oportunidad de la diversidad trinitaria que se revela como cincel de unidad y dignidad para quienes conforman una ciudad.

Entonces, la teología de lo urbano es una forma de hablar de la verdad cristiana en su forma encarnada en la vida contemporánea de los discípulos y las comunidades en la moderna ciudad secular (VINCENT, 1983, p. 4; ZARNOW, 2018, p. 185).

\section{La vida de barrio: La manifestación de Dios en lo cotidiano}

El barrio tiene una especial relevancia dentro de la ciudad, ya que se le ha considerado como el bloque básico, o el lugar de la comunidad local, a partir del cual es posible mantener una cohesión social, muchas veces considerada en crisis por la existencia de una evidente saturación de pobreza y desigualdad en zonas de las grandes ciudades (FORREST, 2009, p. 129). Posee un conjunto de atributos cuyas características son: (i) infraestructura (ii) estatus de clase de la población residente, (iii) servicios públicos, (iv) medioambientales, (v) conectividad (vi) políticas, (vii) las interacciones sociales y (viii) emocionales (GALSTER, 2001, p. 2112). Todas ellas asociadas a una conjunción de diversos usos de suelo, citando como ejemplo usos como residencias, plazas, comercio, y otros.

En este espacio se pueden establecer relaciones de confianza, de gratuidad y solidaridad; donde niños, jóvenes y adultos mayores pueden relacionarse con rostro humano, compartiendo intereses comunes, enriqueciéndose con experiencias diversas y aportando, desde la diversidad, en una construcción comunitaria íntegra e integradora. Por lo tanto, el desafío es el de una pastoral creativa e inteligente capaz de desarrollar estructuras que respondan 
a demandas diferenciadas, no limitándose a una simple minoría (FAJE, 1996, p. 6). El Papa Francisco lo recuerda en su llamada a la integración:

Al mismo tiempo, la creatividad debería llevar a integrar los barrios precarios en una ciudad acogedora: ¡Qué hermosas son las ciudades que superan la desconfianza enfermiza e integran a los diferentes, y que hacen de esa integración un nuevo factor de desarrollo! ¡Qué lindas son las ciudades que, aun en su diseño arquitectónico, están llenas de espacios que conectan, relacionan, favorecen el reconocimiento del otro! (LS, n. 152).

La vida de barrio muestra que otra cultura, aparte del dinero y el poder, es posible. Que en muchas ocasiones la dimensión comunitaria abnegada y solidaria es la expresión viva de un Dios solidario que da la vida por los pobres y marginados; donde optar por ellos es un imperativo ético, como el papa Francisco lo develó en Laudato si (LS) (ANDRADE, 2019, p. 462).

\section{Experimentando lo cotidiano como trascendente}

¿Puede haber trascendencia en lo cotidiano? ¿Qué es, de lo cotidiano, lo que se ilumina con una estrategia de acción Pastoral Urbana? Para responder hay que considerar que, aunque es comprendido como aquello que puede ser poco trascendente y banal en su continua repetición, hay una imposibilidad de imaginar una experiencia sin esa cotidianeidad. Por eso, en su cualidad de auto creación permanente se produce el relato de una existencia marcada por las demandas de insertarse en una vida social, lo que le dota de una cualidad dual (SANTOS HERCEG, 2014, p. 184). Es desde su in-significancia, donde es posible lograr la trascendencia.

Es en lo cotidiano del amor de unos por los otros, en la esperanza ante la adversidad y la muerte, y en la fe de una mejor calidad de vida personal y barrial, en donde la presencia de Dios se hace cotidianidad liberadora y salvadora. Esto muestran los relatos de las vivencias de un grupo de familias residentes en el barrio puerto de la ciudad de Valparaíso, especialmente aquellas que participan de los diversos grupos que acoge la Parroquia de La Matriz, y posibilita la reflexión en torno a la experiencia de una cotidianeidad trascendente. Las memorias reconstruyen lo in-significante del día a día, que expresa temores, prejuicios, pero también expresan aquello que los conecta y donde la Iglesia, como acción transformadora va tomando un lugar en de ellos. Sonia expresa ese cambio en la mirada del otro, ya que las personas del 421 son indigentes, alcohólicos y drogadictos que van a un comedor comunitario:

Y también como que les tenía miedo a las personas del 421, a las caras que tenían y todo así, como que siempre arrancaba, siempre arrancaba de todo este sector. Y resulta que ahora, hoy en día, bueno, hace como... gracias también a la Iglesia que vengo siempre los domingos a misa, me encanta estar en eso, 
entonces vengo a las nueve y media y a las doce, y escuché un aviso de la universidad que estaban haciendo cursos de repostería. Hice el curso, y ahora vengo todos los domingos con pastelitos en la puerta de la Iglesia. Y como que aprendí a convivir con todas esas personas a las que yo les tenía miedo, y ahora les regalo pastelitos, me dicen cosas, y como que aprendí ya a ver que esa gente no es porque sean indigentes, porque sean pobres, todos tienen una historia, todos tienen una historia. ${ }^{2}$

En los relatos se elabora lo cotidiano y se muestra la presencia transformadora de la Iglesia en la construcción de comunidad. Una que necesita comprender el barrio desde las claves que lo definen como lugar hermenéutico, donde sus significados son elaborados dialógicamente desde su dimensión histórica, espacial y social. Desde estas pistas se posibilita explorar la trascendencia de lo cotidiano y cómo la acción pastoral participa y transforma en la revelación del mensaje de Dios.

\subsection{La clave histórica: barrio La Matriz}

Valparaíso, es una ciudad puerto iniciada en el año 1536 cuyas particularidades resultan de la historia que la ha ido forjando. Durante la época colonial se mantuvo como pueblo portuario, alternándose desastres naturales junto con los destrozos causados por piratas. Fue habitado de manera esporádica, con pocas casas, una iglesia y un muelle construido por iniciativa privada recién en 1810 .

En la segunda mitad del siglo XIX, la ciudad alcanza su esplendor, estableciéndose en ella gran cantidad de inmigrantes, en su mayoría europeos y estadounidenses, que ayudaron a darle un marcado aspecto cosmopolita. Este crecimiento explosivo de su población movió las casas hacia los cerros, dándole las características de un anfiteatro natural. Cada uno de ellos, fue adquiriendo características urbanas y sociales diferentes, fragmentándose en barrios con identidad propia. Desde la segunda mitad del siglo XX. la actividad portuaria disminuyó, provocando el deterioro de la ciudad.

El barrio puerto posee dos cualidades relevantes. Primero que es barrio fundacional de la ciudad de Valparaíso, decretado patrimonio de la humanidad en el 2003; y segundo que ha crecido en torno a la iglesia La Matriz. Ella, además de ser patrimonio histórico (existe desde 1559), tiene una acción gravitante en el desarrollo de esa comunidad, aspecto que le da una fuerte identidad local, hasta el punto de que es también llamado barrio la Matriz.

Una primera Parroquia, construida de paja y barro en 1559 por Rodrigo González de Marmolejo, fue saqueada por Drake (1578), incendiada por

\footnotetext{
${ }^{2}$ Relato de Sonia, vecina del barrio. Grupo focal 1 del 25 de mayo de 2019, en casa parroquial.
} 
Spilbergen (1615). Hubo una segunda, que fue destruida por el terremoto de 1730. Una tercera fue terminada en 1749, guiada por el párroco José Pozo y Silva. Contaba con 2 torres pero el terremoto de 1751, destruyó una de ellas y el de 1822 produjo nuevos daños. Aunque siguió usándose, permaneció en estado ruinoso hasta que en 1837 el párroco José Antonio Riobó la demolió. La actual iglesia se construyó entre 1837 y 1842 y fue declarada monumento en 1971; la designación del Salvador del Mundo como patrono de La Matriz fue por votación popular en 1868 (LOPEZ, 2007, p. 1).

\subsection{La clave espacial: vivir en La Matriz}

El barrio, pese a pertenecer al corazón fundacional de la ciudad, mantiene en su zona plana una densidad de apenas 16 hab/há ${ }^{3}$ y se presenta más densamente poblado en la parte alta de la ciudad, (2,4 veces más). Este alto porcentaje que vive en los cerros confirma la condición de pobreza que afecta a esa ciudad, ya que este territorio se caracteriza por agrupar las manzanas de menores ingresos y los campamentos. De hecho la alta densidad se explica por eso, ya que prácticamente no existen edificios en altura (PODUJE, 2018, p. 9).

A ello se suma que el sector es también un lugar excluido de los planes de desarrollo del municipio, pese a ser declarado patrimonio de la humanidad, factor que le da un aspecto ruinoso a su infraestructura y una percepción de pobreza y marginación de sus habitantes.

...en este barrio puerto de Valparaíso, viven personas en la calle, aunque no siempre en situación de calle; ellas son mujeres y hombres que tienen la Plaza Echaurren como living, las veredas de las calles como balcones y el comedor solidario (Ver video del Comedor 421), servido por la Parroquia La Matriz, como comedor. Son hermanos y hermanas que han pasado años compartiendo sus vidas en lugares públicos. Son conocidos por todos y, a veces, queridos por pocos; son fieles rostros que permiten identificar el barrio fundacional de Valparaíso con rastros de dolores, penas y sueños. (DIÓCESIS DE VALPARAÍSO, 2015, p. 1)

La parroquia, se enclava como un eje neurálgico del paisaje y un referente en el espacio, con un atrio alrededor del cual se congregan actividades religiosas y laicas (ferias, actos y ceremonias). Su permanente imagen en las fotos del lugar la han convertido en un agente relevante para el desarrollo religioso, económico y social del barrio.

\subsection{La clave social: La pregunta acerca del otro}

Es así como "La Matriz", ya sea como capilla o como parroquia, se ha enlazado desde siempre con los habitantes, organizando estos su vida en

${ }^{3}$ Datos del censo realizado en el año 2017. 
torno a ella. La acción pastoral sobre esa comunidad la abre al mundo contemporáneo, confrontándose con los desafíos que conlleva ser sensible con las necesidades comunitarias y con la historia del lugar. Sonia, una vecina, lo expresa cuando dice: "y por cosas del destino donde, yo siempre venía de arriba a esta Iglesia porque me encantó, y porque me sentía bien aquí, encontré todo lo que necesitaba acá" ${ }^{4}$.

Ha permitido convertir "la casa de Dios" en la "casa de todos" brindando un sentido de localización al lugar de la iglesia en su comunidad (YIP; LEE; TANG, 2020, p. 17). Gaudium et Spes (GS) ya señaló estos desafíos:

Las nuevas condiciones ejercen influjo también sobre la vida religiosa. Por una parte, el espíritu crítico más agudizado la purifica de un concepto mágico del mundo y de residuos supersticiosos y exige cada vez más una adhesión verdaderamente personal y operante a la fe, lo cual hace que muchos alcancen un sentido más vivo de lo divino. (GS, n. 7)

Como eje de la acción pastoral, está la salvación de la persona humana y su renovación en la sociedad, abrazando al sujeto humano en su unidad experiencial: cuerpo y alma, corazón y conciencia, inteligencia y voluntad (HURTADO, 1987, p. 354). Por ello, se hace ineludible preguntarse acerca del otro develando un posicionamiento ideológico y un distanciamiento cultural (ZAPATA, 2008, p. 60), propio de una singularidad en el otro presente en el ser humano (AGUIRRE; JARAMILLO, 2006, p. 52), el cual perturba y compromete el mundo del enunciante y se presenta como lo extraño y ajeno (PEPERZAK, 1993, p. 1).

Verónica, expresa claramente esta singularidad del otro y la oportunidad de cambiar la mirada: "yo ahí empecé a conocer a esa gente así, a ya no tenerles miedo como antes. Yo ahora converso con ellos, me gusta conversar con ellos, encuentro que ellos dan una gran lección de vida, o sea, al menos a mí" 5 .

Se hace relevante prestar atención a los repertorios narrativos que se van organizando para describir y justificar las formas de relación, porque:

La compasión va unida a la memoria porque solo quien mantiene el recuerdo de los que sufren se empeña en trabajar porque la historia no se repita, sino que se supere. Al mismo tiempo, exige la lógica de la asimetría, donde la preocupación por las/los otros/as supera la relación simétrica que nos sitúa en lo inmediato y, en términos económicos, en la lógica del mercado. La asimetría responde a una articulación entre política y moral, donde la pregunta por la suerte del otro, ocupa un lugar central. (VÉLEZ et al., 2014, p. 238)

\footnotetext{
${ }^{4}$ Relato de Sonia, vecina del barrio. Grupo focal 2 del 26 de mayo de 2019, en casa parroquial.

${ }^{5}$ Relato de Verónica, vecina del barrio. Grupo focal 1 del 25 de mayo de 2019, en casa parroquial.
} 


\section{Relatos, cotidianeidad y el rol transformador de la evangelización}

En las historias de los habitantes se produce una elaboración de otro que, en su diferencia y lejanía, va fortaleciendo la pertenencia a una cultura tanto del sujeto denunciante como del sujeto enunciado. Ello, porque los relatos desde la propia memoria posibilitan una síntesis de las propias tensiones y el descubrimiento de nuevos márgenes de autonomía y posibilidades de acción, de manera que aquellas no contadas y reprimidas dan paso a historias efectivas, de las cuales el sujeto puede hacerse cargo (DEL MASTRO, 2014, p. 2). Así, el lugar emerge en sus significados y con ello se ve cómo la Iglesia se hace parte en ellos, porque en lo cotidiano se va manifestando la presencia de otro, de lo cual se hace necesario tomar conciencia y hacer una apropiación de una óptica de la conversión pastoral. Esta se abre a la novedad del Espíritu para renovar (hacer nuevo) un estilo evangelizador, con un sentido fraterno, reconociendo lo distintivo junto con encontrarse en lo semejante, lográndose que la justicia halle su lugar en el pequeño encuentro intrascendente con el otro. Es también un camino para convertir el propio lugar y su historia, en un antecedente de la acción evangelizadora permitiendo devolver la voz a grupos invisibilizados (SCHICKENDANTZ, 2020, p. 671).

$\mathrm{Al}$ trabajar en la recuperación de las memorias cotidianas a través de los relatos del barrio, se resignificaron sus espacios y encontraron aquello en común, que les diera sentido como comunidad. Desde sus nudos narrativos, se conectaron en una clave espacial y social, como vecinos, como sujetos y les permitió reconocerse como una comunidad solidaria. Una historia elaborada alrededor de los juegos, los negocios, la vida bohemia y los cerros con sus escaleras, donde emerge la iglesia tanto como un referente en el espacio material, como en su interacción en el barrio. Así, va tomando un lugar relevante en la construcción de lo cotidiano.

Los relatos en torno a los juegos agrupan historias de infancia y posicionan primeramente a los narradores con una presencia física y corporal en el barrio. Para ellos, hablar de cómo jugaron, con quien y dónde lo hicieron les permite elaborar un mapa de relaciones afectivas como sujetos vinculados y vinculantes. Relatos de juegos que ya no se practican o en espacios perdidos para tal fin abren la puerta hacia la nostalgia, pero que reflejan también las formas de explorar el mundo, sobre las cuales los hablantes dan cuenta. Emerson lo relata, con una iglesia como escenario para juegos:

Pero bajando por la primera escala, claro. Bueno, y habían negocios, jugábamos en la iglesia abajo, y unas de las cosas características que había aquí, es que aquí se hacían bautizos. Entonces, el bautizo salía por esta puerta, la puerta por la cual entramos, entraban por ahí y salían por ahí los bautizos. Entonces, 
nosotros esperábamos a los padrinos, los padrinos nos tiraban monedas, así que un día sábados todos a recoger monedas. ${ }^{6}$

Esta añoranza los conecta también con la familia y sus ritos religiosos, los moviliza hacia nuevas formas de pensar el barrio y a explorar cómo se conecta en la religiosidad, porque el escenario es el atrio de la parroquia. Así los relatos vinculados a los juegos los trasladan hacia un espectro emocional y en las formas en que ellos convivían y generaban comunidad en el barrio, conectando su historia personal con la impronta de la parroquia en la historia de la familia. Sonia lo expresa cuando recuerda: “[...] entonces mi mamá de chica me llevaba a la iglesia y me incentivaba de que yo llevara una vida en la iglesia, que mi juventud la viviera igual como la vivió ella en la iglesia $[\ldots]^{\prime \prime 7}$.

Los negocios a través del relato los conectan con un habitar el barrio y se ve en ellos simbolizados el sentido de progreso económico y de oportunidades que ofrece, porque hoy Valparaíso y en especial el barrio del puerto viven un lento y difícil resurgimiento, de la mano del rescate de su patrimonio y del empuje motivado por su condición de patrimonio de la humanidad y una nueva bohemia. La llegada de migrantes, y la pandemia, trajo además una nueva pobreza y marginación donde el barrio se presenta en una develación de contrastes ante una iglesia qué democratiza estos espacios, pero mantiene presente una opción preferencial por los pobres. En esta memoria de Rosa, se muestra la acción transformadora de una iglesia vinculada, ya que el comedor 421 es un espacio de voluntariado con gran significado para el barrio:

Entonces, qué pasó: ahí en la pastoral como les digo empecé a conocer este tipo de gente que vivía aquí. Me gustaba porque algunos decían "mire, yo soy carpintero, yo fui esto, yo fui lo otro". En una ocasión, nos invitaron a colaborar al 421, y a mí, me puse a conversar con la gente, y un hombre viejísimo me dijo "yo soy dibujante técnico", me dijo, "yo les trabajaba a los arquitectos, estuve trabajando con los arquitectos de no sé qué universidad" o no sé qué, y a mí ese hombre se me ha iluminado en mi interior. ${ }^{8}$

El grupo de relatos, en torno a la vida bohemia, resulta especialmente interesante. El barrio, en su carácter de puerto, tuvo un carácter fuertemente bohemio donde el paso del día a la noche estableció la frontera entre lo familiar y lo mundano. Desde sus orígenes como un pequeño caserío conlleva una identidad fuertemente arraigada en su vida nocturna desde antiguas chinganas y cantinas, hasta la fiesta interminable del siglo XX, que surgió en torno a la vida del puerto. Aún percibido como un barrio bravo, donde entran los valientes, también es centro de reunión de artistas,

\footnotetext{
${ }^{6}$ Relato de Emerson, vecino del barrio. Grupo focal 2 del 26 de mayo de 2019, en casa parroquial.

${ }^{7}$ Relato de Sonia, vecina del barrio. Grupo focal 1 del 26 de mayo de 2019, en casa parroquial.

${ }^{8}$ Relato de Rosa, vecina del barrio. Grupo focal 1 del 25 de mayo de 2019, en casa parroquial.
} 
escritores, poetas y músicos (PAYÁ, 2011, p. 229). Así queda, en la narrativa colectiva, la noción de una gran noche porteña donde convivieron artistas, intelectuales, parroquianos, trabajadores, cafiches, mafiosos, ricos y pobres, hasta la década de los '70, cuando, producto del golpe de estado, se puso fin a la bohemia como era hasta entonces conocida (LASTARRIA, 2016, p. 53). Juan expresa la cotidianeidad con la que se unen ambas dimensiones, como un sello identitario del lugar.

Acá, al costado de la Matriz, aquí donde estamos acá, al costado ahí donde está la 421, acá al edificio, todo ese sector de allá había unas casas que también eran como tipo conventillo. No conventillo como que tú te metes como un cité, no eran cité; conventillo era, abría las puertas y había piezas, entonces habían burdeles de homosexuales, de mujeres, cachay, que están al costado, muchos años estuvieron ahí. Y esas cosas pasaban abajo, a Cajilla abajo, al mismo al otro lado donde usted dice, donde ahí cercano estaba... donde vendían pescado, se acuerdan. ${ }^{9}$

La Iglesia, siempre presente en los escenarios de los relatos, aparece posteriormente como el lugar donde se dirigían a expiar sus pecados. La opción de participar de la acción parroquial en su comuna los transforma y libera, permitiéndoles convivir en esta mixtura de virtud pecaminosa.

En los relatos, no queda excluido el paisaje de Valparaíso, que marca fuertemente a sus habitantes. Las escaleras en su ascenso (o descenso) señalan también los espacios de encuentro y reconocimiento con los vecinos. Lugares de encuentro entre los vecinos, de vivencias se va entretejiendo en las historias de maneras tan diversas como los son los múltiples pasajes $\mathrm{y}$ accesos a sus residencias. Estos cerros muchas veces se articulan como laberintos para quien no pertenece a ellos; por ello, su presencia narrativa va revelando una identidad y una forma de expresar la presencia del otro en la vida cotidiana. El campanario de La Matriz es un punto espacial de referencia, creando la relación de un ir hacia ella en la acción cotidiana, esto, aun cuando pasa desapercibido en lo cotidiano, va creando un fuerte sentido de apropiación hacia la iglesia.

Desde lo cotidiano se articulan emociones y espacio y una construcción de comunidad, permitiendo a los sujetos una revelación de sí mismos, como capaces de trascender en las relaciones que tiene con los lugares en los que se propician encuentros. Así se va organizando un espacio geográfico no solo en la materialidad del espacio sino en las conexiones emocionales que produce la relación con este espacio y con los sujetos que comparten (PILE, 2010, p. 7).

La acción pastoral se posibilita entonces en la forma en que la parroquia se va entretejiendo como parte de estas historias. Juan lo relata,

\footnotetext{
${ }^{9}$ Relato de Juan, vecino del barrio. Grupo focal 2 del 26 de mayo de 2019, en casa parroquial.
} 
al mantener vivo el nombre de los sacerdotes y cómo estuvo presente en su historia:

Bueno, yo soy nacido acá. [...] puedo decir que, en esta iglesia estaba el padre Pérez, no me acuerdo la verdad hace cuántos años, y el padre Pérez... fuimos en total, en todos, los que nacimos acá hasta el último fuimos como 30 niños, que nacimos en este alrededor, y de esos 30 niños el padre Pérez nos bautizó, hicimos la Primera Comunión, la Confesión con él, y algunos se llegaron a casar y él los casó. Y... hay tantas cosas acá, a ver, se puede decir, nosotros veníamos todos los domingos a misa, el padre Pérez nos conocía a todos y sabía del que no iba el día domingo y nos regañaba en la semana "tú no viniste a la misa del domingo". ${ }^{10}$

Se produce una relación didáctica entre lo cotidiano y lo trascendente; $\mathrm{y}$, de modo inverso, entre lo trascendente y lo cotidiano. Sin lo urbano, considerado como el espacio natural en el que se manifiesta la revelación de Dios, es muy difícil acoger su mensaje de salvación en favor de los seres humanos. Esta acción, sin trascendencia del día a día, produce un encuentro con el otro en la oportunidad misma del encuentro (o del desencuentro); esto supone, además, la decisión explícita de abrirse al otro como un legítimo otro. Verónica nos muestra una Iglesia que se presenta como promotora de estos encuentros, como actos casuales que resultaron significativos para ella:

La secretaria de acá de la Iglesia era mi compañera de mi gimnasio, o sea, asistíamos a un gimnasio, y ella siempre me hablaba del padre Gonzalo, de la Iglesia, de la parroquia acá, y todo, y que era súper feliz acá. Y un día me trajo, y mi sobrinita hizo la primera comunión. Aquí hizo la primera comunión. Bueno, en esos años yo tenía hartos problemas personales, estaba súper agobiada por muchas cosas, personales, y cuando llegué acá a la Iglesia me encontré... me sentí muy acogida, como que sentí mucha paz y como que, ni siquiera, a ver, no opté nunca por ir a otra Iglesia, sino que altiro yo dije "aquí me quedo". ${ }^{11}$

Esto se cruza con una realidad del barrio puerto, donde la presencia de micro tráfico y la delincuencia han fragilizado el tejido social, replegando a las familias hacia sus casas y exacerbando el individualismo. Hay una invitación a preguntarse: ¿Cómo pensamos teológicamente sobre la naturaleza de la iglesia y su misión en la ciudad? (BAKKE, 1992, p. 4), porque la mirada evangelizadora necesita de un diálogo para una atenta escucha de lo que el Espíritu dice a través de la realidad urbana y de los ciudadanos, de manera que se pueda adaptar la acción a esa realidad discernida (MANCERA, 2012, p. 43), cuya finalidad es la transformación en lo que refiere a la dignidad humana.

\footnotetext{
${ }^{10}$ Relato de Emerson, vecino del barrio. Grupo focal 2 del 26 de mayo de 2019 en casa parroquial.

${ }^{11}$ Relato de Verónica, vecina del barrio. Grupo focal del 26 de mayo de 2019 en casa parroquial.
} 
Por ello lo urbano con un sentido pastoral es también una revalorización del otro como la presencia de Cristo en el prójimo. A esto, que se podría llamar contemplación urbana, se refiere el Papa cuando señala:

El universo se desarrolla en Dios, que lo llena todo. Entonces hay mística en una hoja, en un camino, en el rocío, en el rostro del pobre. El ideal no es sólo pasar de lo exterior a lo interior para descubrir la acción de Dios en el alma, sino también llegar a encontrarlo en todas las cosas...». (LS, n. 233)

En la misión eclesial, la conversión pastoral sólo es posible al estar atentos a lo que sucede en el contexto urbano donde la Iglesia vive y actúa. Porque

La pastoral de la Iglesia no puede prescindir del contexto histórico donde viven sus miembros. Su vida acontece en contextos socioculturales bien concretos. Estas transformaciones sociales y culturales representan naturalmente nuevos desafíos para la Iglesia en su misión de construir el Reino de Dios. De allí nace la necesidad, en fidelidad al Espíritu Santo que la conduce, de una renovación eclesial, que implica reformas espirituales, pastorales y también institucionales. (DAp, n. 367)

La eficacia y el poder transformador del Evangelio y de la evangelización, afirma el Papa Pablo VI, llegan entonces hasta el ámbito de la cultura del hombre y de todos los hombres: "[...] evangelizar, no de una manera decorativa, como un barniz superficial, sino de manera vital, en profundidad y hasta sus mismas raíces, la cultura y las culturas del hombre [...]" (EN, n. 20). Este in-trascendente de la revelación de Dios en el barrio permite una reflexión teológica acerca del sentido de su presencia desde lo cotidiano. La revelación de Dios es, entonces, 'rebajada' a una revelación en el seno de la conciencia humana (FONTANILLE, 2015, p. 326), pero no sólo asume un carácter individual, sino social y comunitario. Esto pone de relevancia que no hay nada en el mundo que no haga algún tipo de alusión a la revelación de Dios. "Cuando tomamos conciencia del reflejo de Dios que hay en todo lo que existe, el corazón experimenta el deseo de adorar al Señor por todas sus criaturas..." (LS, n. 87).

Una fe que no crea cultura, o no fue suficientemente anunciada, o no fue objetivamente asimilada o no fue plenamente vivida (NIÑO, 2010, p. 407) y no permite explicar que "Dios habita en la ciudad", ya que el fenómeno urbano se convierte en una "cultura adveniente" propia del ejercicio teológico (GALLI, 2014, p. 288; MENA, 2017, p. 15), porque cultura es

una actividad mediante la cual el ser humano se cultiva a sí mismo y procura acceder a la plenitud de su humanidad. Corresponde al cuidado por la dimensión interior. Cada persona asimila los valores de lo verdadero, lo bello, lo bueno y justo. Es cada vez más humana, de modo más pleno. (PCC, 2012, p. 1)

El barrio, como propio de la ciudad, es una realidad sensible donde se manifiesta la palabra de Dios y en consecuencia la Iglesia no puede excluirse. El Papa Francisco advierte que "debemos recordar siempre que 
Dios no ha abandonado la ciudad; Él vive en la ciudad[...] Dios nunca está ausente de la ciudad, porque nunca está ausente del corazón del hombre" (FRANCISCO, 2015a, p. 2).

$\mathrm{Al}$ evangelizar, la Iglesia humaniza y civiliza desde un vínculo didáctico en la relación entre iglesia-mundo, porque "la vida cristiana no se expresa solamente en las virtudes personales, sino también en las virtudes sociales y políticas" (DAp, n. 505). Luego no es posible una acción pastoral que se desvincule de las múltiples interconexiones de la realidad urbana, como es el barrio. Más aún "la Iglesia debe renovar la capacidad contemplativa de la fe para 'ver' el rostro de Dios en la ciudad" (GALLI, 2014, p. 162).

"Gracias mamita", o "¿tiene un pancito?". Son muy agradecidos. Es lo que más me impresiona a mí, lo que más me gusta de aquí de este barrio, que tal como les decía denantes, que aquí en esta parroquia se hacen conexiones muy bonitas, relaciones muy bonitas, también en la calle. ${ }^{12}$

La pastoral urbana, anclada en el barrio, necesita propiciar una misión evangelizadora que conlleve una transformación social potenciando la dignidad humana de quienes comparten en el sector su vida cotidiana, dado que "el reino [...] contempla una trasformación positiva de toda realidad humana" (PRINZIVALLI, 2018, p. 255).

\section{Conclusiones}

Dos preguntas guían la exploración del presente texto: ¿Cómo lo cotidiano es expresado en los encuentros y relatos de sus habitantes? y ¿Qué impronta tiene la acción pastoral en estos relatos? Los relatos de los vecinos muestran que comprender que Dios habita en la ciudad es hacerse parte de la cultura que como tal se enraíza en las diversas prácticas cotidianas como una pastoral inculturada, es decir, un proyecto de vida plena capaz de desentrañar el mensaje cristiano sobre la ciudad, iluminando las diversas tareas a las que son llamados los creyentes, iluminando los distintos dilemas que la ciudad latinoamericana propone.

Además se produce en lo cotidiano la manifestación de una pastoral urbana donde la revelación de Dios va tejiendo las maneras en que la comunidad se vincula entre sí y a la vez aborda su proyecto de vida. Se vuelve así una realidad sensible que confronta al ser humano, pues se ofrece en una dimensión dual de trascendencia y pecado, en donde en la construcción de un otro como sujeto se está jugando el rastro interpelado del rostro de Cristo en medio de lo cotidiano.

${ }^{12}$ Relato de Verónica, vecina del barrio. Grupo focal 2 del 26 de mayo de 2019. 
El barrio, como unidad comunitaria dentro de la ciudad, permite la relación con sus cotidianeidades. Para el barrio la Matriz, la significación del lugar $\mathrm{y}$, particularmente, el rol con que la parroquia se conecta en los relatos de la comunidad permite un dialogo evangelizador. El significado que toma para la construcción de comunidad los relatos en torno a los juegos, los negocios, la vida bohemia y las escaleras y cerros permiten recuperar la memoria de un lugar, donde el prójimo comparte solidariamente la cotidianeidad y la iglesia se incultura en la vivencia personal y colectiva.

La acción pastoral requiere una conexión más dialéctica de las comunidades en sus entornos existenciales más directos debido a la fragmentación que caracteriza a las ciudades latinoamericanas. La persona que va a ser evangelizada, lejos de ser un ente abstracto, se construye como un ser sujeto a los problemas sociales y económicos del lugar y de su comunidad, manifestando cómo entre evangelización y promoción humana (desarrollo, liberación) existen lazos muy fuertes. En este sentido, la pastoral urbana, considerando los barrios puede suscitar un camino evangelizador al revelar lo trascendente que se revela en lo inmanente de toda acción humana en su hábito social y de barrio. 


\section{Siglas}

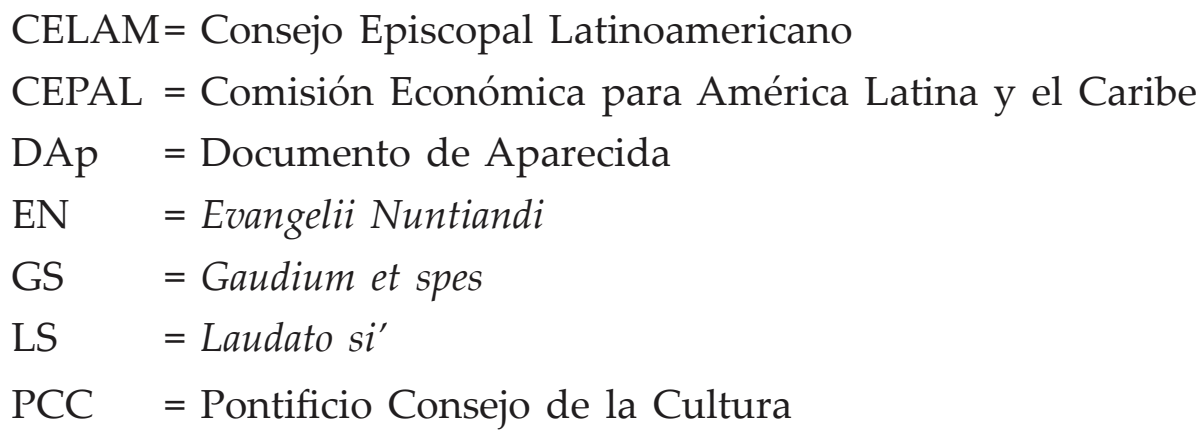

\section{Referencias}

AGUIRRE, J.; JARAMILLO, L. El otro en lévinas: una salida a la encrucijada sujeto-objeto y su pertinencia en las ciencias sociales. Revista Latinoamericana de Ciencias Sociales, Niñez y Juventud, Manizales, v. 4, n. 2, p. 47-71, 2006.

BAKKE, R. J. The Urban Church in Global Perspective: Reflections on the Past, Challenges for the Future. Transformation: An International Journal of Holistic Mission Studies, Oxford, v. 9, n. 2, p. 2-5, 1992.

BRIGHENTI, A. Nueva evangelización y conversión pastoral: un abordaje desde la Iglesia en América Latina y el Caribe. Theologica Xaveriana, Bogotá, v. 63, n. 176, p. 331-366, 2013.

BUENO, E. Dios vive en la ciudad: evangelizar la cultura urbana. Cantabria: Universidad de Cantabria, 2016.

CHEUICHE, A. Cultura urbana: reto a la Evangelización. En: AAVV (Ed.). Cultura y evangelización en América Latina. Santiago de Chile: Paulinas-Ilades, 1988. p. 241-259.

COMBLIN, J. Teología de la ciudad. Estella: Verbo divino, 1972.

COMISIÓN ECONÓMICA PARA AMÉRICA LATINA Y EL CARIBE. La urbanización presenta oportunidades y desafíos para avanzar hacia el desarrollo sostenible. Notas de la CEPAL, n. 73, Agosto 2012. Disponible en: https://www.cepal.org/notas/73/ Titulares2.html. Acceso en: 22 de sept. 2021.

CONSEJO EPISCOPAL LATINOAMERICANO. Documento de Aparecida: Documento Conclusivo del V Conferencia General del Episcopado de América latina y el Caribe. Consejo Episcopal latinoamericano. Aparecida: CELAM, 2007.

DEL MASTRO, C. La interioridad patética del relato: de la alteridad narrativa de Ricœur a la cultura de la vida auto-afectiva henriana1. En: DEL SUJETO TRASCENDENTAL AL COGITO HERIDO 2014, Anales IX Jornadas de fenomenología y hermenéutica. Lima: PUCP, 2014.

DIÓCESIS DE VALPARAÍSO. Una misión diferente: bares y calles del barrio Puerto en Valparaíso. Valparaíso: 8 ene. 2015. Disponible en: https://www.obispadodevalparaiso. cl/detalle.php?id=OTI=. Acceso en: 22 de septiembre 2021. 
ECKHOLT, M. 'Ser huésped de otro'. Fundamentos de formación religiosas en tiempos de globalización e interculturalidad. Teología y Vida, Santiago de Chile. v. 59, n. 4, p. 597-620, 2018.

EDITORIAL. Os desafios da Pastoral Urbana. Perspectiva Teológica, Belo Horizonte. v. 28. n. 74. p. 5-9. 1996. Disponible en: http://faje.edu.br/periodicos/index.php/ perspectiva/article/view/996. Acceso en: 22 de septiembre.

FITZGERALD, P. Doing theology in the city. CrossCurrents, [s. 1.], v. 51, n. 1, p. 83-94, 2001.

FONTANILLE, J. La inmanencia: ¿estrategia del humanismo? Tópicos del Seminario, Puebla, v. 1, n. 33, p. 291-331, 2015.

FORREST, R. Who cares about neighbourhoods? International Social Science Journal, Londres, v. 59, n. 1, p. 129-141, 2009.

FRANCISCO, Papa. Discurso del santo padre francisco a los participantes en la plenaria del consejo pontificio para los laicos. Vaticano: Libreria Editrice Vaticana, 2015a. Disponible en: http://www.vatican.va/content/francesco/es/encyclicals/documents/ papa-francesco_20150524_enciclica-laudato-si.pdf. Acceso: 22 sept. 2021.

FRANCISCO, Papa. Carta encíclica Laudato si. Vaticano: Librería Vaticano, 2015b.

FORTE, B. La Teología como compañía, memoria y profecía. Salamanca: Sigueme, 1990.

GALLI, C. M. Dios vive en la ciudad. Buenos Aires: Agape, 2014.

GALSTER, G. On the nature of neighbourhood. Urban Studies, Glasgow, v. 38, n. 12, p. 2111-2124, 2001.

GATICA, F. La urbanización en América Latina: Aspectos espaciales y demograficos del crecimiento urbano y de la concentración de población. Notas de Población n. 9 . CEPAL. Disponible en https://repositorio.cepal.org/handle/11362/12563. Acceso en: 22 de sept. 2021.

CONSTITUCIÓN Pastoral Gaudium et Spes sobre la iglesia en el mundo actual. CONCILIO VATICANO II. Vaticano: 7 dez. 1965. Disponible en: https:// www.vatican.va/archive/hist_councils/ii_vatican_council/documents/vat-ii_const _19651207_gaudium-et-spes_po.html . Acceso en: 22 de septiembre 2021.

HAGOPIAN, F. Latin American Catholicism in an Age of Religious and Political Pluralism: A Framework for Analysis. Comparative Politics, New York, v. 40, n. 2, p. 149-168, 2008.

HOLYOAKE, G. J. The principles of secularism. Londres: London, Book store; Austin \& co, 1870. Disponível en <https://archive.org/details/principlesofsecu00holy/page/ n7> Acceso en: 22 de sept. 2021.

HURTADO, F. El hombre centro de la acción pastoral. Revista Javeriana, Bogotá, v. 37, n. 85, p. 353-363, 1987. Disponível en: https://revistas.javeriana.edu.co/index. php/teoxaveriana/article/view/22229/17293. Acceso en: 22 de sept. 2021.

JANOSHCKA, M. El nuevo modelo de la ciudad latinoamericana: fragmentación y privatización. EURE, Santiago de Chile, v. 28, n. 85, p. 11-29, dic. 2002.. 
KOSMIN, B. A. Hard and soft secularists and hard and soft secularism: An intellectual and research challenge. En: SOCIETY FOR THE SCIENTIFIC STUDY OF RELIGION. ANNUAL CONFERENCE 2006, Oregon. Anais... Oregon.

LARRAÍN, J. Identidad cultural del chileno. Buenos Aires: LOM, 1984.

LASTARRIA, C. Barrio Puerto: de los orígenes a la bohemia en Valparaíso. Santiago: Narrativa punto aparte, 2016.

LOPEZ, A. Parroquia de la Matriz. 2007. Disponível en: http://valpoiglesias.blogspot. com/2007/08/parroquia-de-la-matriz.html. Acceso en: 22 de sept. 2021.

MANCERA, J. Culturas urbanas y prácticas pastorales : evangelización , complejidad urbana y conversión pastoral. Teología y Sociedad, Bogotá, v. 9, n. 2012, p. 27-45, 2012. Disponível em: revistas.javerianacali.edu.co/index.php/teologiaysociedad/ article/view/369. Acceso en: 22 de sept. 2021.

MARTINS, A. A. Ética social católica y salud pública: en busca de una bioética de liberación. Perspectiva Teológica, Belo Horizonte, v. 51, n. 3, p. 461-480, set./dez. 2019.

MENA, M. Bibia y Ciudad: Pedagogías del bien vivir en contextos urbanos. Bogotá: Universidad Santo Tomás, 2017.

NEWMANN, P. The theology of sustainability practice: How cities create hope. En: Handbook of Engaged Sustainability. p. 297-308. E-book.

NIÑO, F. De la pastoral en la ciudad a la pastoral urbana. Cuestiones Teológicas, [s. 1.], v. 37, n. 88, p. 399-416, 2010.

PABLO VI, Papa. Exhortación apostólica Evangelii Nuntiandi. Roma: 1975. https://www. vatican.va/content/paul-vi/es/apost_exhortations/documents/hf_p-vi_exh_19751208_ evangelii-nuntiandi.html. Acceso en: 22 de sept. 2021.

PAYÁ, E. Valparaíso: la vieja y nueva bohemia. Rev Chil Infect, [s. 1.], v. 28, n. 3, p. 229, 2011.

PEPERZAK, A. To the Other: An Introduction to the Philosophy of Emmanuel Lévinas. [s.1.] : Purdue University Press, 1993. Disponível en: https://www.jstor. org/stable/j.ctt6wq31c. Acceso en: 22 de sept. 2021.

PONTIFICIO CONSEJO DE LA CULTURA. Los desafíos que enfrenta la iglesia en la evangelización de la cultura. Primeras jornadas de fe y cultura. Tucumán Argentina. 2012

PILE, S. Emotions and affect in recent human geography. Transactions of the Institute of British Geographers, Londres, v. 35, n. 2010, p. 5-20, 2010.

PODUJE, I. El despoblamiento de valparaiso. Valparaíso: ATISBA, 2018.

PRINZIVALLI, E. Sentido del tiempo y movimiento del pensamiento histórico en el cristianismo desde sus orígenes hasta Eusebio de Cesarea. Teología y Vida, Santiago de Chile, v. 2, n. 59, p. 253-285, 2018.

SANTOS HERCERG, J. Cotidianeidad, trazos para una conceptualización filosófica. Alpha, Osorno, n. 38, p. 173-196, 2014. 
SCHICKENDANTZ, C. ¿El vaticano al servicio de la interculturalidad y de un giro decolonial? Un proyecto intercontinental en desarrollos. Perspectiva Teológica, Belo Horizonte, v. 52, n. 3, p. 661-679, set-dez. 2020.

SOLÍS BELLO, D. Religión y construcción simbólica de territorios identitarios urbanos en la ciudad de Guadalajara: El Bethel y Santa Cecilia. Cuicuilco, [s. 1.], v. 17, n. 49, p. 261-282, 2010. Disponível em: http://www.scielo.org.mx/pdf/cuicui/ v17n49/v17n49a14.pdf. Acceso en: 22 de septiembre 2021.

SZUPIANI, E. La ciudad fragmentada. Estudios Sociales Contemporaneos, Mendoza, n. 19, p. 99-116, 2018.

VÉLEZ, C. et al. El desplazamiento forzado: un desafío a la pastoral (sub)urbana. Franciscanum 161, Bogotá, v. 56, n. 2014, p. 221-256, 2014.

VINCENT, J. J. Towards An Urban Theology. New Blackfriars, Oxford, v. 64, n. 751, p. 4-17, 1983.

YIP, M. K. C.; LEE, J. W. Y.; TANG, W. S. From God's home to people's house: Property struggles of church redevelopment. Geoforum, Amsterdam, v. 110, p. 14-24, 2020.

ZAPATA, C. Edward Said y la otredad cultural. Atenea, Concepción, v. 498, n. 2008, p. 55-73, 2008.

ZARNOW, C. Urbane Theologie. Zeitschrift fur Theologie und Kirche, [s. 1.], v. 115, n. 2, p. 185-208, 2018.

Artículo presentado en 20.04.2021 y aprobado en 11.10.2021.

Dr. Gonzalo Arturo Bravo Álvarez es doctor en Teología Bíblica en la Pontificia Universidad Gregoriana de Roma. Decano de la Facultad Eclesiástica de Teología en la Pontificia Universidad Católica de Valparaíso (PUCV) y Obispo en la diócesis de San Felipe de Aconcagua. Contribución al artículo: enfoque de contenido sobre la teología de lo urbano, la acción pastoral y análisis de los datos recopilados.

Orcid.org/0000-0003-4892-4854. E-mail: gonzalo.bravo@pucv.cl

Dirección: Avda. Brasil, 2950

Valparaíso, Chile

Dr. Maite Inés Jiménez Peralta es doctor en Psicología por la Pontificia Universidad Católica de Valparaíso (PUCV). Profesor y miembro del observatorio de responsabilidad social en la misma institución. Contribución al artículo: enfoque de contenido sobre la alteridad, diseño metodológico en la producción y análisis de los datos recopilados. Orcid.org/0000-0003-28481662 E-mail: maite.jimenez@pucv.cl

Dirección: Avda. Brasil, 2950

Valparaíso, Chile 